\title{
Return to Play after Modified Broström Operation for Chronic Ankle Instability in Elite Athletes
}

\author{
Kyungtai Lee, MD, Hyuk Jegal, MD, Heewoong Chung, MD*, Younguk Park, MD* \\ Foot and Ankle Service, KT Lee's Orthopedic Hospital, Seoul, \\ *Department of Orthopedic Surgery, Ajou University Hospital, Ajou University School of Medicine, Suwon, Korea
}

\begin{abstract}
Background: This study assessed the average time to return to training and official game participation after modified Broström operation (MBO) in elite athletes.

Methods: Sixty athletes diagnosed with lateral ankle instability underwent MBO from October 2011 to December 2013. Their average age was 19.3 years, and the average follow-up time was 28.8 months. We measured the time sequence of three phases of rehabilitation: start of personal training, start of team training, and start of the first official game after recovery. Patients were divided into an early return to play (RTP) group and late RTP group. The groups were compared to identify possible risk factors affecting the RTP time.

Results: The mean length of time to return to personal training was 1.9 months, return to team training was 2.9 months, and return to competitive play was 3.9 months. There were no significant differences of any variables including age, sex, body mass index, level of sports, grade of instability, presence of os subfibulare, and preoperative functional score between the early RTP and late RTP groups.

Conclusions: The RTP was $83.3 \%$ at 4 months after lateral ankle ligament repair and 100\% at 8 months postoperatively. The results provide reference data for orthopedic surgeons in evaluating surgical results and informing patients about expectations after surgery in terms of performance level and timing of return to sports.

Keywords: Lateral ankle instability, Modified Broström operation, Return to play
\end{abstract}

The ankle is the most common location of injury during sports activities. ${ }^{1)}$ Ankle sprains account for $76.7 \%$ of injuries, followed by skeletal injuries. Lateral ankle sprains account for $13 \%$ to $56 \%$ of all injuries in sports requiring running or jumping, such as soccer, basketball, and volleyball. ${ }^{2)}$ Lateral ankle sprain can be treated conservatively with casting, bracing, medications, and rehabilitation exercises. Despite adequate trials with conservative treatment, about $30 \%$ of all patients with acute ligamentous injuries

Received August 28, 2018; Accepted November 5, 2018

Correspondence to: Younguk Park, MD

Department of Orthopedic Surgery, Ajou University Hospital, Ajou University School of Medicine, 164 World cup-ro, Yeongtong-gu, Suwon 16499, Korea

Tel: +82-31-219-5220, Fax: +82-31-219-5229

E-mail: parkyounguk@gmail.com have chronic symptoms. Chronic ankle instability is one of the most common of these residual problems. ${ }^{3,4)}$

When conservative treatments fail to give satisfactory function and stability, operative treatment should be considered. Reports on the modified Broström operation (MBO) have demonstrated promising functional outcomes in the literature, with the majority of patients having good-to-excellent results. ${ }^{5-7)}$ This surgical procedure is the gold standard for the treatment of patients with objective and subjective instability. Lee et al. ${ }^{6}$ reported excellent long-term results at a mean of 10.6 years following $\mathrm{MBO}$ without calcaneofibular ligament reconstruction, with 28 of the 30 patients returning to their preinjury levels.

When treating elite athletes, one of the first questions asked of the doctors is when they will be able to train and go back to field again. The average time to return to activities in a general population may not be applicable 
Lee et al. Return to Play after Modified Broström Operation

Clinics in Orthopedic Surgery • Vol. 11, No. 1, $2019 \bullet$ www.ecios.org

to the elite athlete. Obviously, this problem is not a "black or white" decision. Rather, the return is a gradual process. Nevertheless, it should be decided when this process can be initiated. If this decision is not made carefully, substantial consequences as well as prolonged absence might result. $^{8)}$

MBO was hypothesized to be a safe and effective surgical method for chronic ankle instability and provide an expected return to competitive play at approximately 4 months. There has been scarce literature to guide athletes as to their predicted time to return to training and to competitive sport. The purpose of the study was to assess the average time to return to training and return to play (RTP) following $\mathrm{MBO}$ in elite Korean athletes. The second aim was to find out the rate of return to previous level of sports activity, performance level at the final follow-up and, finally, rational causes of delayed recovery.

\section{METHODS}

This study was approved by the Institutional Review Board of Ajou University Hospital (IRB No. AJIRB-MEDMDB-16-097). Between August 2013 and December 2013, A total of 54 athletes underwent MBO for chronic ankle instability by a single surgeon (YP). These patients were retrospectively reviewed under IRB-approved waived consent. The elite athletes included in the study were registered on the Korean high level or junior level athlete lists.

The indications for operative intervention were intractable pain or symptom of instability after remote ankle sprain affecting sports performance refractory to conservative treatment like strengthening exercises and physical rehabilitation for at least 3 to 6 months. Thirty-six patients (36 feet) were excluded from this study due to short follow-up period ( $<2$ years, $n=7$ ), additional surgery ( $n$ $=20)$, previous surgery $(n=6)$, and lower limb malalignment requiring surgery $(n=3)$. A total of 18 patients were included in this study (nine males and nine females; average age, 19.3 years; range, 13 to 23 years). Seven patients were junior level and 11 were high level athletes. Sports activities at the onset of symptom included soccer $(n=8)$, basketball $(n=2)$, ballet and gymnastics $(n=3)$, martial arts $(\mathrm{n}=2)$, and others $(\mathrm{n}=3)$.

\section{Surgical Procedure}

The surgical procedure involved was anterior talofibular ligament imbrication with reinforcement of the inferior extensor retinaculum. $\left.{ }^{6}\right)$ Detailed procedures were identical to those described in the previous literature. ${ }^{9)}$ Stability was then checked and the skin was closed. After surgery, ankles were protected by immobilization for 4 weeks and an ankle brace (Aircast Air-Stirrupbrace; DJO Global, Vista, CA, USA) for 2 weeks. At 4 weeks postoperatively, gentle range of motion (ROM) exercises were encouraged as much as possible. At 6 weeks, strengthening exercises of the ankle and Achilles tendon stretching exercises were started. Full weight bearing was allowed when a patient achieved full ankle ROM. Six weeks after surgery, patients could progress from walking, to jogging, to running, to figure of eight running, and to lateral cutting back and forth. Details of rehabilitation were previously described. ${ }^{10)}$

We reviewed our clinical and operative notes. We measured the time sequence of three phases of rehabilitation: start of personal training (jogging or jumping and late rehabilitation phase), start of team training (return to sport), and start of the first official game (i.e., RTP). We divided the patients into the early RTP group and late RTP group based on the mean time to RTP (start of the first official game). Variables including age, sex, body mass index (BMI), presence of os subfibulare, and grade of instability were compared between the two groups to identify possible risk factors that can affect the RTP time.

\section{Statistical Analyses}

All continuous variables are expressed in terms of the mean and standard deviation. Some ordinal variables (grade of instability and level of sports) were expressed for each number of ranks. A nonparametric statistical analysis method (Mann-Whitney $U$-test) was employed to compare the two groups with respect to age, BMI, grade of instability, and level of sports. Chi-square test was used to evaluate the effect of sex and the presence of os subfibulare. Statistical significance was accepted for $p<0.05$.

\section{RESULTS}

All eighteen patients returned to the previous level of activities without any surgical complications. All patients were continuing to train and compete symptom-free at an average follow-up of 28 months. There were no reoperations, infections, or neurovascular damage.

The mean follow-up was $28.8 \pm 4.3$ months (range, 25 to 38 months). The average age of the players was 19.3 \pm 3.0 years (range, 13 to 24 years). The mean length of time to return to personal training postoperatively was 1.9 \pm 1.2 months (range, 1 to 6 months), return to team training was $2.9 \pm 1.0$ months (range, 1 to 6 months), and RTP was $3.9 \pm 1.4$ months (range, 2 to 7 months). The RTP was by 4 months in 15 patients and 7 months in the remaining 3 (Table 1). 
Lee et al. Return to Play after Modified Broström Operation

Clinics in Orthopedic Surgery • Vol. 11, No. 1, 2019• www.ecios.org

The patients were divided by the mean time to return to competitive play at 3.9 months. The athletes who returned to competitive play before 3.9 months were assigned to the early RTP group and the athletes who returned later than 3.9 months were allocated to the late RTP group. There were no significant differences in age, sex, BMI, level of sports, grade of instability, presence of os subfibulare, and preoperative functional score (American Orthopedic Foot and Ankle Society Ankle-Hindfoot score) between the early and late RTP groups (Table 2).

\section{DISCUSSION}

Recovery progression after an injury or surgery in an elite athlete may be different from that of the recreational sports person. One might assume that, because of the very high levels of performance expected, the elite athlete may take longer to return to a preinjury level than the average person. However, better access to expert aftercare by dedicated physical therapists and issues of motivation often

\section{Table 1. Time to Return to Each Activity in Two Groups}

\begin{tabular}{|lcc|}
\hline \multicolumn{1}{|c}{ Variable } & $\begin{array}{c}\text { Early RTP } \\
(\mathrm{n}=8)\end{array}$ & $\begin{array}{c}\text { Late RTP } \\
(\mathrm{n}=10)\end{array}$ \\
\hline Return to personal training (mo) & $1.6 \pm 0.5$ & $2.2 \pm 1.5$ \\
\hline Return to team training (mo) & $2.6 \pm 0.5$ & $3.2 \pm 1.2$ \\
\hline Return to competitive play (mo) & $2.9 \pm 0.3$ & $4.8 \pm 1.3$ \\
\hline
\end{tabular}

Values are presented as mean \pm standard deviation.

RTP: return to play. mean that a high-performance athlete rehabilitates more quickly. ${ }^{8)}$

Running is allowed in more than 16 weeks after Broström repair in general; ${ }^{10)}$ providing a reference for return to running. Athletic patients will often be significantly quicker than this. RTP can vary in meaning from study to study. We measured the time sequence of three phases of rehabilitation: start of personal training, start of team training (return to sport), and start of first official game (RTP). Therefore, our results provide a reference for the sequence of decisions that need to be made for the ultimate goal of RTP.

White et al. ${ }^{11)}$ reported early resumption of athletic activity after surgery. Based on club medical records, the median time to return to training for athletes was 63 days (range, 49 to 152 days) and the median time to play was 77 days (range, 56 to 178 days). The timings reflected the judgment that the athletes were medically fit and available for team selection. This is a bit different from our definition, the time from surgery to participation in the first official game. In terms of return to team training (2.9 months) and first official game (3.9 months) in this series, the results are similar with those in the literature. ${ }^{10,12,13)}$

In the current study, possible variables that might delay RTP were compared between the early and late RTP groups. These included age, sex, BMI, grade of instability, presence of os subfibulare. Younger athletes are more likely to return to their preinjury level of sport after anterior cruciate ligament reconstruction. ${ }^{14)}$ Men are approximately 1.5 times more likely than women to return to either their previous level of sport or competitive sport. ${ }^{15)}$ In the current study, there were no differences in age, sex and BMI

Table 2. Possible Factors Influencing Return to Play

\begin{tabular}{|lccc|}
\hline \multicolumn{1}{c}{ Variable } & Early RTP $(\mathrm{n}=8)$ & Late RTP $(\mathrm{n}=10)$ & $p$-value \\
\hline Age $(\mathrm{yr})$ & $18.1 \pm 3.1$ & $20.3 \pm 2.8$ & 0.173 \\
\hline Sex (male:female) & $5: 3$ & $4: 6$ & 0.637 \\
\hline Body mass index $\left(\mathrm{kg} / \mathrm{m}^{2}\right)$ & $22.5 \pm 1.2$ & $21.2 \pm 1.5$ & 0.068 \\
\hline AOFAS Ankle-Hindfoot score (preoperative) & $69.9 \pm 6.5$ & $69.8 \pm 6.4$ & 0.965 \\
\hline AT & $6.2 \pm 1.0$ & $6.5 \pm 1.3$ & 0.965 \\
\hline TTA & $14.3 \pm 2.5$ & $16.0 \pm 3.4$ & 0.274 \\
\hline ADT & $3.0 \pm 0.0$ & $2.7 \pm 0.5$ & 0.315 \\
\hline Presence of os subfibulare & 3 & 3 & 0.142 \\
\hline
\end{tabular}

Values are presented as mean \pm standard deviation.

RTP: return to play, AOFAS: American Orthopedic Foot and Ankle Society, AT: anterior translation on anterior drawer stress radiographs before operation, TTA: talar tilt angle on varus stress radiographs before operation, ADT: grade of anterior drawer test before operation. 
Lee et al. Return to Play after Modified Broström Operation

Clinics in Orthopedic Surgery • Vol. 11, No. 1, 2019• www.ecios.org

Table 3. Details of the Three Delayed Return to Play Cases

\begin{tabular}{ccclcccc} 
No. & Age (yr) & Sex & Sports & $\begin{array}{c}\text { Beighton } \\
\text { score }\end{array}$ & $\begin{array}{c}\text { Return to } \\
\text { personal training (wk) }\end{array}$ & $\begin{array}{c}\text { Return to } \\
\text { team training (wk) }\end{array}$ & $\begin{array}{c}\text { Return to } \\
\text { competitive play (wk) }\end{array}$ \\
\hline 1 & 19 & Female & Ballet & 9 & 24 & 24 & 28 \\
\hline 2 & 22 & Female & Gymnast & 9 & 4 & 4 & 28 \\
\hline 3 & 23 & Female & Gymnast & 7 & 4 & 12 & 24 \\
\hline
\end{tabular}

between the two groups.

Athletes should be aware that associated injuries may delay return and symptoms may continue. ${ }^{11)}$ White et al. ${ }^{11)}$ reported that the median time to full training was statistically significant between athletes with isolated lateral ligament injuries and those with associated injuries. We tried to find out the cause of delay of return. MBO with subfibular ossicle excision reportedly provides similarly good clinical and radiographic outcomes compared with the same procedure without subfibular ossicle excision. ${ }^{16)}$ In this study, there was no significant difference in the presence of os subfibulare between the two groups. Also, there was no significant difference in the time to RTP between the ossicle group and no ossicle group $(p=0.964)$.

$\mathrm{MBO}$ has been shown to produce good results for patients with chronic ankle instability, regardless of the grade of instability on the preoperative stress radiographs. ${ }^{17)}$ Similarly, we did not observe any significant difference in the grade of instability between the two groups.

Generalized laxity is associated with recurrent instability after ankle ligament reconstruction. ${ }^{18,19)}$ Direct repair of the ligaments in patients with generalized joint hypermobility presents a significant risk for mechanical failure of the procedure. ${ }^{19)}$ Gross ligamentous laxity (Beighton score $>4$ ) was suggested as a possible indicator of increased risk of reinjury. ${ }^{20)} \mathrm{A}$ more recent study reported that the MBO may be successful in patients with chronic ankle instability and with generalized laxity, as determined by a Beighton score $>4 .{ }^{21)}$ Presently, three patients experi- enced a later return to competitive athletics (Table 3). They were relatively young and female (one was a ballerina and two were gymnasts). Their Beighton scores were 9, 9, and 7. This might be associated with their very late RTP.

The current study has some limitations. The primary limitation is the small number of individuals. We excluded 36 patients among 54. Major exclusion criteria were additional surgery and short follow-up. An athlete seldom experiences just a ligament problem; usually, cartilage or tendon or other problems are present. Another limitation of this study is that different sports or athletic activities were involved, making it impossible to assess the influence of different characteristics of each sport. However, we believe that the results can be a general guideline for diverse sports and athletic activities.

Most athletes (83.3\%) returned to preinjury level sports activity by 4 months and all resumed participation 8 months after lateral ankle ligament repair. All were actively participating in their sports or athletic activity at the final follow-up. The results could provide reference information for orthopedic surgeons to evaluate surgical results and inform patients about what they should expect after surgery in terms of performance level and timing of RTP.

\section{CONFLICT OF INTEREST}

No potential conflict of interest relevant to this article was reported.

\section{REFERENCES}

1. Gabbe BJ, Finch CF, Wajswelner H, Bennell KL. Predictors of lower extremity injuries at the community level of Australian football. Clin J Sport Med. 2004;14(2):56-63.

2. Ferkel RD, Chams RN. Chronic lateral instability: arthroscopic findings and long-term results. Foot Ankle Int. 2007;28(1):24-31.

3. Hertel J. Functional anatomy, pathomechanics, and pathophysiology of lateral ankle instability. J Athl Train.
2002;37(4):364-75.

4. van Rijn RM, van Os AG, Bernsen RM, Luijsterburg PA, Koes BW, Bierma-Zeinstra SM. What is the clinical course of acute ankle sprains? A systematic literature review. Am J Med. 2008;121(4):324-31.e6.

5. Bell SJ, Mologne TS, Sitler DF, Cox JS. Twenty-six-year results after Brostrom procedure for chronic lateral ankle instability. Am J Sports Med. 2006;34(6):975-8. 
Lee et al. Return to Play after Modified Broström Operation

Clinics in Orthopedic Surgery • Vol. 11, No. 1, 2019• www.ecios.org

6. Lee KT, Park YU, Kim JS, Kim JB, Kim KC, Kang SK. Longterm results after modified Brostrom procedure without calcaneofibular ligament reconstruction. Foot Ankle Int. 2011;32(2):153-7.

7. Tourne Y, Mabit C, Moroney PJ, Chaussard C, Saragaglia D. Long-term follow-up of lateral reconstruction with extensor retinaculum flap for chronic ankle instability. Foot Ankle Int. 2012;33(12):1079-86.

8. Calder JD, Sexton SA, Pearce CJ. Return to training and playing after posterior ankle arthroscopy for posterior impingement in elite professional soccer. Am J Sports Med. 2010;38(1):120-4.

9. Gould N, Seligson D, Gassman J. Early and late repair of lateral ligament of the ankle. Foot Ankle. 1980;1(2):84-9.

10. Pearce CJ, Tourne Y, Zellers J, et al. Rehabilitation after anatomical ankle ligament repair or reconstruction. Knee Surg Sports Traumatol Arthrosc. 2016;24(4):1130-9.

11. White WJ, McCollum GA, Calder JD. Return to sport following acute lateral ligament repair of the ankle in professional athletes. Knee Surg Sports Traumatol Arthrosc. 2016;24(4):1124-9.

12. Li X, Killie H, Guerrero P, Busconi BD. Anatomical reconstruction for chronic lateral ankle instability in the highdemand athlete: functional outcomes after the modified Brostrom repair using suture anchors. Am J Sports Med. 2009;37(3):488-94.

13. Miyamoto W, Takao M, Yamada K, Matsushita T. Accelerated versus traditional rehabilitation after anterior talofibular ligament reconstruction for chronic lateral instability of the ankle in athletes. Am J Sports Med. 2014;42(6):1441-7.
14. Ardern CL, Taylor NF, Feller JA, Webster KE. Fifty-five per cent return to competitive sport following anterior cruciate ligament reconstruction surgery: an updated systematic review and meta-analysis including aspects of physical functioning and contextual factors. Br J Sports Med. 2014;48(21):1543-52.

15. Kondric M, Sindik J, Furjan-Mandic G, Schiefler B. Participation motivation and student's physical activity among sport students in three countries. J Sports Sci Med. 2013;12(1):10-8.

16. Ahn HW, Lee KB. Comparison of the modified Brostrom procedure for chronic lateral ankle instability with and without subfibular ossicle. Am J Sports Med. 2016;44(12):315864.

17. Jeong BO, Kim TY, Song WJ. Effect of preoperative stress radiographic findings on radiographic and clinical outcomes of the modified Brostrom procedure for chronic ankle instability. J Foot Ankle Surg. 2016;55(1):125-8.

18. Colville MR. Reconstruction of the lateral ankle ligaments. Instr Course Lect. 1995;44:341-8.

19. Karlsson J, Bergsten T, Lansinger O, Peterson L. Reconstruction of the lateral ligaments of the ankle for chronic lateral instability. J Bone Joint Surg Am. 1988;70(4):581-8.

20. Petrera M, Dwyer T, Theodoropoulos JS, Ogilvie-Harris DJ. Short- to medium-term outcomes after a modified Brostrom repair for lateral ankle instability with immediate postoperative weightbearing. Am J Sports Med. 2014;42(7):1542-8.

21. Huang B, Kim YT, Kim JU, Shin JH, Park YW, Kim HN. Modified Brostrom procedure for chronic ankle instability with generalized joint hypermobility. Am J Sports Med. 2016;44(4):1011-6. 